\title{
Research on the Price Discovery Function of Chinese Corn Futures Market
}

\author{
Wei GUAN ${ }^{1,2,3, a}$ and Mu ZHANG ${ }^{1, b, ~ * ~}$ \\ ${ }^{1}$ School of Finance, Guizhou University of Finance and Economics, Guiyang Guizhou \\ 550025, China \\ ${ }^{2}$ Guizhou Institute for Urban Economics and Development, Guizhou University of \\ Finance and Economics, Guiyang Guizhou 550025, China \\ ${ }^{3}$ Guizhou Institution for Technology Innovation \& Entrepreneurship Investment, \\ Guizhou University of Finance and Economics, Guiyang Guizhou 550025, China \\ a892412017@qq.com, brim_007@163.com \\ ${ }^{*}$ Corresponding author
}

Keywords: Price discovery function, Vector error correction model, State space model, Kalman filter method.

\begin{abstract}
For researching the function of price discovery in the Chinese corn futures market, this article uses cointegration test, Granger causality test, vector error correction model and state space model to analyze the corn futures market. The empirical results indicate that corn futures market and the spot market have a cointegration relationship, and the spot market price dominates the futures market price. Using the Kalman filter method, the dynamic contribution rate of corn futures market and spot market is calculated. The results show that the corn futures market is in a dominant position of price discovery function. The above results can be drawn of the corn futures market has a certain price discovery function.
\end{abstract}

\section{Introduction}

At present, China's economic development has entered a new normal, economic growth is from high-speed growth to intermediate-speed growth, and the agricultural economy growth has slowed. How to strengthen the agriculture as the foundation continuously and promote the sustainable income in the new normal is one of the major issues that China needs to address currently and urgently. Establishment of agricultural futures markets is to protect the interests of farmers. Due to the formation of the spot market with time-lag, dispersion and blindness, the prices of agricultural products is very unstable. There are price spikes and crash frequently. One of the reasons is the information asymmetry. The spot market cannot collect a wealth of important information of agricultural products to reflect the price. But one important function of agricultural futures market is price discovery function. The agricultural futures market can bring together a wealth of buyer's information to reflect supply and demand effectively, and format a reasonable market price.

Foreign and domestic scholars have made appropriate researches about the futures market price discovery function and effectiveness. Foreign scholars' researches for the futures market price discovery function are more in-depth. Mckenzie and Holt using error correction model on the basis of cointegration test. The results show that the futures and spot markets have a long-term equilibrium [1]. Yan and Zivot indicated that price discovery is the dynamic response of the market price to new information [2]. 
Renan Silverio and Alexandre SzkloKim select the Kalman filtering technique as a new perspective. They use it to study contribution degree of crude oil futures market [3].

The domestic researches on the price discovery function of futures market are not very comprehensive. Jun Wang and Zongcheng Zhang used vector auto regression model, error correction model, the impulse response function, etc. to analyze the soybean and wheat futures market. It is concluded that there exists bi-directional leading relationship between futures and spot prices for two varieties [4]. Kai Liu used state space model to describe the Shanghai copper futures market's price dynamic evolution processes, as well as the London copper futures market. And he used the Kalman filtering method to calculate the dynamic contribution rates of the futures market and the spot market. The empirical results show that the futures market is in the dominant position on price discovery [5].

This article is based on previous studies. We use the state space model to describe the dynamic evolution of the price of corn futures market. In this model, the Kalman filter method is used to calculate the futures market and the spot market dynamics contribution rates. We use the results to reveal price discovery function of Chinese corn futures market. Providing the effective information to calculate the optimal hedge ratio and providing evidence for futures market regulators to make policy.

\section{Empirical Research on Price Discovery Function of Corn Futures Market}

China currently has Zhengzhou Commodity Exchange and the Dalian Commodity Exchange in agricultural futures. The trading products cover China's major agricultural products, including China's three major grains, such as corn, wheat and rice. In the world futures market, corn is a representative variety in agricultural commodities futures. In terms of trading volume and investor participation, it has always been at the forefront of commodity futures. So this paper selects the corn futures market as the research object.

\section{Data Selection and Basic Statistical Characteristics}

Data Sources and Processing. This paper selects the Dalian Commodity Exchange corn futures contracts. In order to reflect prices of corn futures contracts, the paper select the main contract of corn from all contracts. The contract prices constitute a set of consecutive data of market trend. The time span of the data is from October 8, 2012 to September 30, 2015. Select the trading day's closing price of the corn main contract within the time span as the data sample. It obtained 727 data samples. Then select the Zhengzhou wholesale market average price of corn spot as the data sample. Another set of 727 sample data was got in the same time span. These data are from the East Wealth Choice data terminals. Figure 1 describes the corn futures prices and spot prices time series curves.

From the time series curves it can seen, spot price of corn prices have a significant decline in the October 14, 2013 and a significant rise in July 7, 2014. In September 1, 2014 the prices reached the highest point and began to fall. Since the second half of the 2015 , the corn spot prices started to fall significantly; Corn futures prices are more stable, but in the second half of the 2015, the price fluctuation is more intense. It may have a certain relationship with the decline of the spot price of corn. 


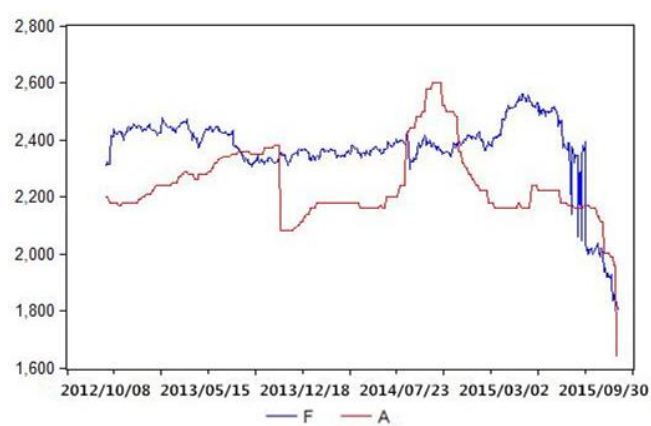

Figure 1. The time series curves of corn futures prices and spot prices

Basic Statistical Characteristics. In order to reduce the heteroscedasticity of the price sequence, we use the logarithmic processing on the corn futures prices and spot prices. Recorded as $\operatorname{Ln}(\mathrm{F})$ and $\operatorname{Ln}(\mathrm{A})$, and recorded the first difference of them as $\Delta \mathrm{Ln}$ (F) and $\Delta \operatorname{Ln}(\mathrm{A})$, this paper applies EViews7.2 statistical analysis software for data analysis. The standard deviation of corn futures prices with logarithmic processing is larger than the spot's, which shows the price fluctuation of corn futures market is more severe. The skewness of corn futures price with logarithmic processing is less than 0 . The skewness of corn futures price with logarithmic processing is slightly more than 0 . The kurtosis of the two is more than 3. It indicated that corn futures price series characteristics are left deviation, spikes and thick tail, corn spot price series characteristics are right deviation, spikes and thick tail, neither obeys the normal distribution.

\section{Empirical Test of the Relationship between the Futures Price and the Spot Price}

Unit Root Test. Before the cointegration test, we need to check whether the data is stationary. This paper uses ADF unit root test method to test the stationarity. The Ln (F) data and $\operatorname{Ln}(\mathrm{A})$ data is non-stationary series. But the $\Delta \mathrm{Ln}(\mathrm{F})$ data is stationary and the $\Delta \mathrm{Ln}$ (A) data is stationary in the level of $10 \%$.

Cointegration Test. Using the Johansen cointegration test methods, we test whether existing a long-term cointegration relationship between the corn futures price and spot price. At the 5\% significance level, there is a cointegrating relationship in corn futures price and spot price. The cointegration equation is:

$$
\operatorname{Ln}(f)=-0.055153 \cdot \operatorname{Ln}(\mathrm{a})-0.0000687 \text {. }
$$

It shows that there is a long-term stationary relationship between $\ln (\mathrm{F})$ and $\ln (\mathrm{A})$. There is a Granger causal relationship on theory.

Causality Test. After the above unit root test and cointegration test, it shows that $\Delta \operatorname{Ln}(\mathrm{F})$ and $\Delta \operatorname{Ln}(\mathrm{A})$ data is stationary, and there is a long-term stationary relationship. It can be used Granger causality test to test several lags respectively. According to the test results, it shows that there is a one-way causality relationship from corn futures prices to spot price. It means that the corn futures prices lead the spot prices. But the corn spot prices do not lead the corn futures prices obviously. It indicated that the corn futures market may have the price discovery function.

\section{Static Contribution of Price Discovery Function in Corn Futures Market}

Introduction of the Vector Error Correction Model. Vector error correction model is based on the cointegration relationship of the series. As it has already test the cointegration relationship between the corn futures prices and spot prices. The test results show that corn futures prices and the spot price existing a long-term equilibrium. If it is subjected to external influences, the equilibrium will deviate. The corn futures 
market can re-find equilibrium by the price discovery function. This section introduces the vector error correction model to research static contribution of the price discovery function in corn futures market.

Construction of the Vector Error Correction Model. The equation of vector error correction model (VEC) is:

$$
\Delta Y_{t}=\alpha \cdot V E C M_{t-1}+\sum_{i=1}^{p-1} \Gamma_{i} \Delta Y_{t-1}+\varepsilon_{t} .
$$

The first item of the equation is the short-term adjustment after the long-term equilibrium of the futures price and the spot price is broken. The second item is the long-term equilibrium relationship between the dependent variable and independent variable of the price series. The third item is the error correction item.

Combined with the above model, a vector error correction model is constructed:

$$
\begin{aligned}
& \Delta F_{t}=\alpha_{t}^{F} \cdot V E C M_{t-1}+C_{1}^{F} \Delta A_{t-1}+C_{2}^{F} \Delta F_{t-1}+\varepsilon_{t}^{F} . \\
& \Delta A_{t}=\alpha_{t}^{A} \cdot V E C M_{t-1}+C_{1}^{A} \Delta A_{t-1}+C_{2}^{A} \Delta F_{t-1}+\varepsilon_{t}^{A} .
\end{aligned}
$$

$\alpha_{t}^{F}$ is the adjustment coefficient of the futures price error correction item. $\alpha_{t}^{A}$ is the adjustment coefficient of the spot price error correction item. $\mathrm{ECM}_{\mathrm{t}-1}$ is the error correction item. $C_{1}^{F}, C_{2}^{F}, C_{1}^{A}, C_{2}^{A}$ is the adjustment coefficient of the short-term price. $\varepsilon_{t}^{F}, \varepsilon_{t}^{A}$ is the independent residuals.

Empirical Study on the Vector Error Correction Model. The long-term equilibrium equation of the corn futures prices and the spot prices is

$$
\begin{aligned}
& \operatorname{Ln}(\mathrm{F})=-10.96572 \operatorname{Ln}(\mathrm{A})+77.47515 . \\
& \operatorname{VECM}_{t-1}=10.96572 \operatorname{Ln}(A)-77.47515-\operatorname{Ln}(F) .
\end{aligned}
$$

The vector error correction model is

$$
\left[\begin{array}{l}
\Delta L A_{t} \\
\Delta L F_{t}
\end{array}\right]=\left[\begin{array}{l}
-0.0004 \\
-0.0004
\end{array}\right]+\left[\begin{array}{cc}
0.032 & 0.026 \\
0.042 & 0.042
\end{array}\right]\left[\begin{array}{l}
\Delta L A_{t-1} \\
\Delta L F_{t-1}
\end{array}\right]+\left[\begin{array}{cc}
0.032 & 0.027 \\
0.014 & 0.353
\end{array}\right]\left[\begin{array}{c}
\Delta L A_{t-2} \\
\Delta L F_{t-2}
\end{array}\right]-\left[\begin{array}{c}
0.003 \\
0
\end{array}\right] V E C M_{t-1}+\hat{\varepsilon}_{t} .
$$

The matrix data of the second item and third item is contribution of the one lag price and two lags price. It can explain the contribution of futures prices and spot prices.

\section{Dynamic Contribution of Price Discovery Function in Corn Futures Market}

Introduction of the State-space Model. The vector error correction model estimated above is to analyze the static contribution of a time point. But it cannot analyze the dynamic contribution of the price discovery function of the futures market. So this paper introduces the state-space model. State-space model can turn the static parameter to dynamic parameter. It is able to estimate the different states with the time go. By introducing the state-space model to evaluate the dynamic contribution of the price discovery function of the futures market.

Construction of the State-space Model. The state-space model of this paper is as follows:

Measurement Equation:

$$
\begin{aligned}
& \Delta \mathrm{LF}_{\mathrm{t}}=\mathrm{A}_{1 \mathrm{t}} \cdot \mathrm{VECM}_{\mathrm{t}-1}+\mathrm{C}_{1}^{\mathrm{F}} \cdot \Delta \mathrm{LF}_{\mathrm{t}-1}+\mathrm{C}_{2}^{\mathrm{F}} \cdot \Delta \mathrm{LA}_{\mathrm{t}-1}+\mathrm{C}_{3}^{\mathrm{F}} \cdot \Delta \mathrm{LF}_{\mathrm{t}-2}+\mathrm{C}_{4}^{\mathrm{F}} \cdot \Delta \mathrm{LA}_{\mathrm{t}-2}+\hat{\varepsilon}_{\mathrm{t}} \cdot \\
& \Delta \mathrm{LA}_{\mathrm{t}}=\mathrm{A}_{2 \mathrm{t}} \cdot \mathrm{VECM}_{\mathrm{t}-1}+\mathrm{C}_{1}^{\mathrm{A}} \cdot \Delta \mathrm{LA}_{\mathrm{t}-1}+\mathrm{C}_{2}^{\mathrm{A}} \cdot \Delta \mathrm{LF}_{\mathrm{t}-1}+\mathrm{C}_{3}^{\mathrm{A}} \cdot \Delta \mathrm{LA}_{\mathrm{t}-2}+\mathrm{C}_{4}^{\mathrm{A}} \cdot \Delta \mathrm{LF}_{\mathrm{t}-2}+\hat{\varepsilon}_{\mathrm{t}} .
\end{aligned}
$$




\section{State Equation:}

$$
\begin{aligned}
& A_{1 t}=A_{1 t-1}+\eta_{1 t} . \\
& A_{2 t}=A_{2 t-1}+\eta_{2 t} .
\end{aligned}
$$

$\Delta \mathrm{LF}_{\mathrm{t}}$ is the first-order differential of futures price. $\Delta \mathrm{LA}_{\mathrm{t}}$ is the first-order differential of the spot price. $\hat{\varepsilon}_{t}$ is the independent residuals. $A_{1 t}$ and $A_{2 t}$ is the state vectors. $\eta_{1 t}$ and $\eta_{2 t}$ is the independent residuals.

According to the model above, it can establish a measure, $\delta$ t, with the time goes. We use it to describe the dynamic contribution of the price discovery function of the futures market:

$$
\delta_{t}^{F}=\left|A_{1 t}\right| /\left(\left|A_{1 t}\right|+\left|A_{2 t}\right|\right) .
$$

the dynamic contribution of the price discovery function of the spot market:

$$
\delta_{t}^{A}=\left|A_{2 t}\right| /\left(\left|A_{1 t}\right|+\left|A_{2 t}\right|\right) \text {. }
$$

Kalman filtering method is used to measure the optimal state quantity of state-space model. And the dynamic contribution of the price discovery function of the futures market and spot market is $\delta_{t}^{F}, \delta_{t}^{A}$.

Empirical Study on the State-space Model. Using the error correction model to estimate the parameters of the measurement and state equations:

$$
\begin{aligned}
& {\left[\begin{array}{l}
\Delta L A_{t} \\
\Delta L F_{t}
\end{array}\right]=\left[\begin{array}{l}
-0.0004 \\
-0.0004
\end{array}\right]+\left[\begin{array}{ll}
0.032 & 0.026 \\
0.042 & 0.042
\end{array}\right]\left[\begin{array}{c}
\Delta L A_{t-1} \\
\Delta L F_{t-1}
\end{array}\right]+\left[\begin{array}{ll}
0.032 & 0.027 \\
0.014 & 0.353
\end{array}\right]\left[\begin{array}{l}
\Delta L A_{t-2} \\
\Delta L F_{t-2}
\end{array}\right]-\left[\begin{array}{c}
0.003 \\
0
\end{array}\right] V E C M_{t-1}+\hat{\varepsilon}_{t} .} \\
& V E C M_{t-1}=10.96572 \operatorname{Ln}(A)-77.47515-\operatorname{Ln}(F) .
\end{aligned}
$$

Set the program statements of the measurement and the state equation in the EViews7.2 software:

@ signal lft $=\mathrm{A} 1 * \mathrm{vecm}+0.042 * 1 \mathrm{ft}(-1)+0.042 * \operatorname{lat}(-1)+0.014 * \operatorname{lat}(-2)+0.353 * 1 \mathrm{ft}(-2)+[\mathrm{var}$ $=\exp (\mathrm{c}(1))]$

@ state $\mathrm{A} 1=\mathrm{A} 1(-1)$

$@$ signal lat $=\mathrm{A} 2 * \mathrm{vecm}+0.026 * 1 \mathrm{ft}(-1)+0.032 * \operatorname{lat}(-1)+0.032 * \operatorname{lat}(-2)+0.027 * 1 \mathrm{ft}(-2)+[\mathrm{var}$ $=\exp (\mathrm{c}(2))]$

@ state $\mathrm{A} 2=\mathrm{A} 2(-1)$

Using the Kalman filtering methods to obtain state vector series, $A_{1 t}$ and $A_{2 t}$, and then obtain the dynamic contribution of the price discovery function of the futures market and spot market is $\delta_{t}^{F}, \delta_{t}^{A}$. The results are shown in the Figure 2.

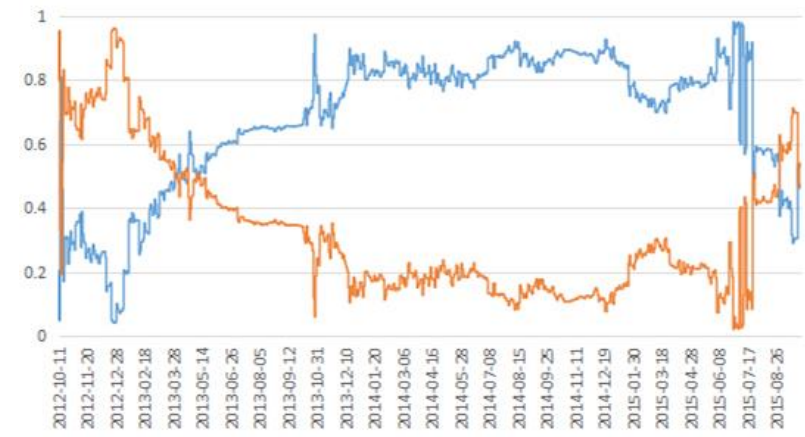

Figure 2. The dynamic contribution degree of the corn futures market and spot market

The empirical results show that: From mid-October 2012 to the end of December 
2012, the contribution degree of the corn futures market is significant weakening; From mid-early January 2013 to June 2015, the contribution degree of the corn futures market is gradually increasing; And from early April 2013, the contribution degree began ahead of the contribution degree of corn spot market; At the end of June 2015, the contribution degree of corn futures prices began to fluctuate, and the contribution of the futures short behind the spot. Most of the time, the contribution rate of futures is more than 0.5. It is in a dominant position, but in some period it is fall behind and volatile severely.

At the end October 2013 and the end of June 2015, the contribution is volatile severely. The corn spot price fell sharply is related to the volatility. At the other times, the performance of the corn futures prices and spot prices are smooth, the contribution degree of the futures market is more stable.

\section{Conclusions and Suggestions}

(1) The cointegration and causality test results show that corn futures market price series has a cointegration relationship and the corn spot price is one-way leading corn futures prices.

(2) From the futures market price discovery function of dynamic analysis results, we can see the dynamic contribution of corn futures market is higher than the corn spot market most of the time; In some special time, the dynamic contribution of corn futures market is less than the spot market. In these periods, the corn spot price fluctuates severely. Overall, most of the time, the corn futures market can effectively play the role of price discovery function.

Based on above, we hereby make the following suggestions:

(1) To strengthen the information disclosure. Market information asymmetry is the important factor that affects the spot prices and futures prices of corn. Only the related department disclosure market information timely, accurately and effectively. The corn futures market can correctly reflect the spot market price.

(2) Open futures market access system. Regulators should encourage and support some institutional investors join into the agricultural product futures market to participate in the investment. On the design of the futures contract, should also tend to be miniaturization.

\section{Acknowledgement}

This work was financially supported by National Natural Science Foundation of China (71263011) and Humanity and Social Science Planning Foundation of Ministry of Education of China (11YJA630196).

\section{References}

[1] A. M. McKenzie, M. T. Holt. Market efficiency in agricultural futures markets [J]. Applied Economic, 2002(34): 1519-1532.

[2] B. C. Yan, E. A. Zivot. Structural analysis of price discovery measures [J]. Journal of Financial Markets, 2010(13): 1-19.

[3] Silverio, S. K. Alexandre. The effect of the financial sector on the evolution of oil prices: Analysis of the contribution of the futures market to the price discovery process in the WTI spot market [J]. Energy Economics, 2012(34): 1799-1808. 
[4] Wang Jun, Zhang Zongcheng. Study on Chinese agricultural futures price discovery based VAR model [J]. Journal of Management, 2005(6): 680-753.

[5] Liu Kai. A comparative study of Chinese and foreign futures market price discovery function from the dynamic perspective [D]. Central South University, Changsha, 2013. 